\title{
Isolated congenital megalocornea
}

INSERM

\section{Source}

INSERM. (1999). Orphanet: an online rare disease and orphan drug data base. Isolated congenitalmegalocornea. ORPHA:91489

Isolated congenital megalocornea is a genetic, non-syndromic developmental defect of the anterior eye segment characterized by bilateral enlargement of the corneal diameter (>12.5 mm) and a deep anterior eye chamber, without an elevation in intraocular pressure. It can manifest with mild to moderate myopia as well as photophobia and iridodonesis (due to iris hypoplasia). Associated complications include lens dislocation, retinal detachment, presenile cataract development, and secondary glaucoma. 